\title{
Algerian Olive Germplasm and Its Relationships with the Central-Western Mediterranean Varieties Contributes to Clarify Cultivated Olive Diversification
}

\author{
Kamel Atrouz ${ }^{1,2}$, Ratiba Bousba ${ }^{2}$, Francesco Paolo Marra ${ }^{3} \mathbb{D}$, Annalisa Marchese ${ }^{4} \mathbb{D}$, Francesca Luisa Conforti ${ }^{5}$, \\ Benedetta Perrone ${ }^{5}$, Hamza Harkat ${ }^{2}$, Amelia Salimonti ${ }^{1}$ (D) and Samanta Zelasco ${ }^{1, *}$
}

1 Council for Agricultural Research and Economics-Research Centre for Olive, Fruit and Citrus Crops, 87036 Rende, Italy; kamalatrouz@gmail.com (K.A.); amelia.salimonti@crea.gov.it (A.S.)

2 Department of Biology and Plant Ecology, Faculty of Natural Sciences and Life, Frères, Mentouri University, Constantine 25000, Algeria; bousbaratiba@gmail.com (R.B.); hamza_harkat@yahoo.com (H.H.)

3 Department of Architecture, University of Palermo, 90128 Palermo, Italy; francescopaolo.marra@unipa.it

4 Department of Agricultural, Food and Forest Sciences, University of Palermo, 90128 Palermo, Italy; annalisa.marchese@unipa.it

5 Department of Pharmacy, Health and Nutritional Sciences, University of Calabria, 87036 Rende, Italy; francescaluisa.conforti@unical.it (F.L.C.); benedetta.perrone90@gmail.com (B.P.)

* Correspondence: samanta.zelasco@crea.gov.it

check for updates

Citation: Atrouz, K.; Bousba, R.; Marra, F.P.; Marchese, A.; Conforti, F.L.; Perrone, B.; Harkat, H.; Salimonti, A.; Zelasco, S. Algerian Olive Germplasm and Its

Relationships with the

Central-Western Mediterranean Varieties Contributes to Clarify Cultivated Olive Diversification. Plants 2021, 10, 678. https:// doi.org/10.3390/plants10040678

Academic Editor:

Ioannis Ganopoulos

Received: 6 March 2021

Accepted: 26 March 2021

Published: 1 April 2021

Publisher's Note: MDPI stays neutral with regard to jurisdictional claims in published maps and institutional affiliations.

Copyright: (c) 2021 by the authors. Licensee MDPI, Basel, Switzerland. This article is an open access article distributed under the terms and conditions of the Creative Commons Attribution (CC BY) license (https:/ / creativecommons.org/licenses/by/ $4.0 /)$.

\begin{abstract}
Olive tree with its main final product, olive oil, is an important element of Mediterranean history, considered the emblematic fruit of a civilization. Despite its wide diffusion and economic and cultural importance, its evolutionary and phylogenetic history is still difficult to clarify. As part of the Mediterranean basin, Algeria was indicated as a secondary diversification center. However, genetic characterization studies from Maghreb area, are currently underrepresented. In this context, we characterized 119 endemic Algerian accessions by using 12 microsatellite markers with the main goal to evaluate the genetic diversity and population structure. In order to provide new insights about the history of olive diversification events in the Central-Western Mediterranean basin, we included and analyzed a sample of 103 Italian accessions from Sicily and, a set of molecular profiles of cultivars from the Central-Western Mediterranean area. The phylogenetic investigation let us to evaluate genetic relationships among Central-Mediterranean basin olive germplasm, highlight new synonymy cases to support the importance of vegetative propagation in the cultivated olive diffusion and consolidate the hypothesis of more recent admixture events occurrence. This work provided new information about Algerian germplasm biodiversity and contributed to clarify olive diversification process.
\end{abstract}

Keywords: Algerian olive germplasm; phylogenesis analysis; biodiversity

\section{Introduction}

The cultivated olive tree, (Olea europaea L. sub-sp. europaea var. bot. europaea) is the symbol of the Mediterranean culture and crucial for the Mediterranean diet [1]. Olive with its main final product, which stands out on our tables and in our kitchens, is also an important element of Mediterranean history, considered the emblematic fruit of a civilization. To put it like the historian Fernand Braudel, "where the olive tree ends, the Mediterranean also ends". However, currently olive growing diffusion has reached a lot of non-traditional producer countries such as Argentina, Australia, Chile, China, and the United States [2]. Despite a wide diffusion and economic and cultural importance of the tree crop, its evolutionary and phylogenetic history is still difficult to clarify [2,3]. The geological period during which the Olea complex originated and began to evolve is difficult to determine; the absence of certain fossil finds makes it difficult to identify a definite epoch. Palaeobotanical data attest to the occurrence of Olea sp. in Europe during 
the Oligocene-Miocene boundary that could be identified as an ancestor of the oleaster (Olea europaea L. sub-sp. europaea var. bot. sylvestris). Phylogenetic analyses have suggested that the most recent common ancestor of the 6 olive subspecies was present during the Late Miocene or Early Pliocene, about 4.0-8.3 million years ago [4]. Besnard et al. [4] indicated the presence of olive trees as a floristic element of African paleotropical origin. Olive trees colonized the Mediterranean area in the Pliocene period and the diversification into the 6 subspecies (subsp. cuspidata, laperrinei, guanchica, maroccana, cerasiformis, europaea) occurred during the last 3-4 million years, following a series of tectonic and climatic events, thus suggesting a specific evolutionary scenario.

Genetic analysis supported the systematic classification and allowed to individuate the subsp. europaea var. bot. sylvestris as the most recent ancestral of the olive tree cultivated for the largest number of shared plastid lines [5]. All six subspecies show distinct plastid lineages that are partially shared among this group. For instance, subsp. laperrinei maintains a shared line with the cultivated olive tree that is not present in subsp. sylvestris [3].

The recent accumulation of palaeobotanical, archeological, historical, and molecular data has contributed to improve knowledge, but further investigations are required to elucidate the processes underlying the primary domestication and subsequent secondary diversification of olives. It is commonly believed that olive domestication occurred in the Near East approximately 6000 years ago. The great civilizations of the eastern Mediterranean, such as the Phoenicians, Greeks and Romans, disseminated this tree crop throughout the Mediterranean basin [5-7]. Further, recent genetic studies demonstrated that as many as $90 \%$ of current cultivars are characterized by the same chloroplast haplotype lineage [3].

The spreading of the olive culture throughout the Mediterranean Basin by human migrations and commercial exchanges has played a key role in determining the current pattern of olive germplasm diffusion. The Maghreb indicates the western most geographical area of North Africa overlooking the Mediterranean Sea and the Atlantic Ocean; originally it concerned the strip of land between the Atlas Mountains and the Mediterranean Sea (northern Tunisia, Algeria and Morocco); some sources also include Islamic Sicily and al-Andalus namely, the Islamic Spain, the name given by the Arabs to the part of the Iberian Peninsula and of Septimania, in the south of France controlled and governed by them. As part of the Mediterranean basin, specifically referred to Maghreb, with a fairly heterogeneous climate between its different regions, Algeria is distinguished by the biological richness of its ecosystems, and it was indicated as a secondary diversification center of several olive subspecies and cultivars [8]. In fact, several cultivars were found, often carrying the name of the farmer who selected them or of the locality where they were grown. This reflected the large number of cultivated varieties, including old or traditional varieties of the country. These genotypes represent an interesting genetic potential for plant breeding programs. Furthermore, despite their abundance, the genetic resources available in Algeria are not sufficiently exploited to improve their performance. Thus, their integration in the breeding programs needs more efforts both in genetic and phenotypic characterization activities. Several prospecting actions have been carried out and variety catalogues have been elaborated in Algeria [9]. However, Algerian germplasm has been only recently studied at molecular level [1,10-12] and just two studies carried out a comparison among a relatively low number of Algerian cultivars with the rest of Mediterranean olive germplasm where hypotheses about olive domestication and migration pathway have been formulated [1,11]. Haddad et al. [1] speculated about the existence of an independent domestication center in the Central Mediterranean area, starting from the observation that Laperrine's olive tree share its haplotype (E1) with most of the world's olive varieties, including $67 \%$ of the Algerian varieties. Di Rienzo et al. [11], using a predictive model, excluded historical migration events between Algerian population and other populations such those from Italy, Syria and Malta, describing a diffusion of olives from Syria to the Greek area, a secondary independent event of domestication from Syria to Spain and a second migration event occurred in Italy and Malte from the Greek area. 
Although these and other recent studies have provided nuclear and chloroplastic genetic profiles for wild olives and cultivars from the central and southern Mediterranean regions, the Algerian germplasm still remains underrepresented [1,10-12].

Efficient and robust molecular markers are increasingly needed for improving varieties, establishing a molecular database for tree identification enabling the spread of common methods for large-scale genetic analysis. At present, Simple Sequence Repeats (SSRs) or microsatellites offer the opportunity to evaluate many potentially polymorphic sites and are the markers of choice for olive DNA fingerprinting and cultivar identification [13]. Microsatellites also have advantages over other PCR-based markers, because they are co-dominant and easily reproducible, and have a frequent and random distribution, allowing a wide coverage of the genome [14,15]. The high level of variation detected with microsatellites increases the resolution for genealogy and germplasm genetic diversity studies [16,17].

In this context, we collected 119 endemic Algerian accessions belonging to two different subspecies (europaea and laperrinei) in the Eastern and Southern Algeria regions, respectively and characterized them by using 12 microsatellite markers with the main goal to evaluate the genetic diversity and population structure of a wider sample of Algerian olive tree. Furthermore, to provide new insights about the history of olive diversification such as bottleneck, migration and other demography events in the Central-Western Mediterranean basin, we included and analyzed 103 samples of Italian accessions from Sicily considering its peculiar geographic position and, a set of molecular profiles from French, Tunisian, Moroccan, and Spanish cultivars representative of Central-Western Mediterranean area from our internal database. The phylogenetic investigation of 461 genotypes let us to evaluate genetic relationships among Central-Mediterranean basin olive germplasm, highlight new synonymy cases to support the importance of vegetative propagation in the cultivated olive diffusion and consolidate the hypothesis of more recent admixture events occurrence.

\section{Results}

\subsection{Genetic Diversity and Polymorphism of SSR Markers in Algerian Population}

One hundred nineteen accessions including 109 cultivars, 8 putative wild or feral olive trees, and 2 individuals belonging to Olea europaea subsp. laperrinei were fingerprinted using 12 SSR loci. A total of 127 alleles were obtained, with sizes varying from the shortest allele with $100 \mathrm{bp}$ for UDO 15 to the longest allele with $308 \mathrm{bp}$ for OLEST 14 (Table 1). The number of alleles per locus ranged from 6 in the SSR locus OLEST 23 to 16 for the DCA 8 locus, with a mean of 10.6 alleles, revealing a high level of variability in the sample set. The number of effective alleles (Ne) per SSR ranged from 1.46 (OLEST 23) to 8.42 (DCA 18), with a mean of 4.06. The observed (Ho) and expected (He) heterozygosity ranged from 0.275 (UDO 15) to 0.945 (DCA 18) and from 0.67 (EMO 90) to 0.885 (DCA 18), with a mean of 0.72 and 0.77 , respectively. In fact a Ho significant deficiency was observed for three loci (UDO 15, UDO 12, and DCA 11) with a corresponding very high positive value for both the inbreeding coefficient (Fis) and the probability of null alleles F (Null). Shannon's information index (I) showed the lowest value 1.37 at locus EMO 90 and the highest value 2.23 at locus DCA 18. Polymorphic information content (PIC) value ranged for the same markers from 0.621 to 0.869 with an average of 0.74 (Table 1). All the microsatellite loci showed higher value of PIC $>0.5$ and could be classified as highly informative. 
Table 1. Diversity parameters detected in the Algerian sample of 119 accessions for each of 12 Simple Sequence Repeats (SSR) marker used: size range, number of detected alleles (No), number of effective alleles $(\mathrm{Ne})$, observed $\left(\mathrm{H}_{\mathrm{O}}\right)$ and $(\mathrm{He})$ expected heterozygosity, significance of (HW) test, frequency of null alleles F (null), Inbreeding coefficient (Fis), polymorphic information content (PIC), Shannon's information index (I). ${ }^{* * *}$ High significance; ${ }^{* *}$ significance, NS: not significan, ND: not determined.

\begin{tabular}{ccccccccccc}
\hline Locus & Size Ranges (bp) & No & Ne & Ho & He & HW & F(Null) & Fis & PIC & I \\
\hline DCA18 & $167-189$ & 12 & 8.42 & 0.95 & 0.89 & ND & -0.036 & -0.0786 & 0.869 & 2.23 \\
DCA03 & $228-257$ & 14 & 6.53 & 0.86 & 0.85 & NS & -0.007 & 0.0069 & 0.828 & 2.04 \\
DCA08 & $119-159$ & 16 & 6.02 & 0.86 & 0.84 & NS & -0.018 & -0.0568 & 0.812 & 2.05 \\
OLEST14 & $268-308$ & 13 & 5.33 & 0.84 & 0.82 & NS & -0.019 & -0.0146 & 0.789 & 1.90 \\
OLEST7 & $260-281$ & 8 & 1.72 & 0.82 & 0.80 & NS & -0.014 & -0.0138 & 0.772 & 1.72 \\
GAPU71B & $121-147$ & 7 & 4.68 & 0.86 & 0.79 & NS & -0.045 & -0.0953 & 0.754 & 1.64 \\
DCA11 & $130-163$ & 12 & 1.70 & 0.48 & 0.76 & $* * *$ & 0.224 & 0.347 & 0.719 & 1.70 \\
OLEST23 & $203-222$ & 6 & 1.46 & 0.89 & 0.76 & $* *$ & -0.087 & -0.2026 & 0.711 & 1.46 \\
UDO15 & $100-123$ & 10 & 3.54 & 0.28 & 0.72 & $* * *$ & 0.454 & 0.6151 & 0.678 & 1.55 \\
DCA05 & $192-222$ & 14 & 3.25 & 0.73 & 0.69 & NS & -0.031 & -0.0948 & 0.670 & 1.71 \\
UDO12 & $150-166$ & 8 & 2.98 & 0.44 & 0.67 & $* * *$ & 0.209 & 0.319 & 0.627 & 1.37 \\
EMO90 & $186-202$ & 7 & 3.09 & 0.66 & 0.67 & NS & -0.014 & 0.0008 & 0.621 & 1.37 \\
Mean & & 10.6 & 4.06 & 0.72 & 0.77 & & & & 0.74 & 1.73 \\
\hline
\end{tabular}

The observed frequency of the detected 127 alleles ranged from 0.004 to 0.529 , with a mean of 0.0945 (Supplementary Materials Table S1). The highest frequency value (0.529) was shown for the allele $206 \mathrm{bp}$ at locus DCA 8 while 63 rare alleles were detected (frequency $<5 \%$ ), representing almost $50 \%$ of the total of 127 amplified alleles. New alleles were detected for almost all the SSR loci: $137 \mathrm{bp}$ (GAPU 71b), $228 \mathrm{bp}$ (DCA 3), $119 \mathrm{bp}$ and $125 \mathrm{bp}$ (DCA 8), $192 \mathrm{bp}$ and $222 \mathrm{bp}$ (DCA 5), $202 \mathrm{bp}$ (EMO 90), $153 \mathrm{bp}$ and $162 \mathrm{bp}$ (UDO 12), $109 \mathrm{bp}$ and $113 \mathrm{bp}$ (UDO 15), $278 \mathrm{bp}$ and $281 \mathrm{bp}$ (OLEST 7), and $268 \mathrm{bp}$ and $305 \mathrm{bp}$ (OLEST 14), found exclusively in one single accession, most of them in subsp. laperrinei (Tables S1 and S2). The unweighted pair group method with arithmetic mean (UPGMA) dendrogram (Figure 1) showed the genetic relationships among the 119 genotypes analyzed, based on the set of 12 microsatellite loci used. Genetic similarity ranged from 0 to 1.00 , with a value of the cophenetic correlation coefficient $r=0.73(p<0.001)$ interpreted as a good fit for clustering analysis. The clustering analysis based on Dice coefficient showed two reallydifferent clusters where the subsp. laperrinei was in a single cluster showing a Dice coefficient range between 0 and 0.38 . The main cluster included cultivated and putative wild olive genotypes. These genuine olive genotypes did not show a restricted distribution in a single sub-cluster except for WO Kella, Wo Ouled tag, and WO Atounsi but wide genetic variability was however detected among them (Dice coefficient range from 0.48 to $0.7)$. In the main cluster, six sub-clusters were distinguishable. Two sub-clusters showed a high genetic diversity among olive genotypes even if collected under the same province such in the case of accessions 'Ballouti' (Zareza mila) and the accession 'Messisni ronde' (Old city mila) $40 \mathrm{~km}$ far from each other. Overall, no clear grouping of cultivars in relation to geographical location was observed, except for subsp. laperrinei but clustering seemed mostly related to the fruit end-use (Table S3). The majority of genotypes used as table olives and/or dual use were grouped in a distinct sub-cluster. It is worth to note that three putative wild (or feral) olive trees ('WO Harrouche', 'WO Bourghoud 2', and 'WO Bourghoud 1') characterized by large fruit size were included in this cluster. 


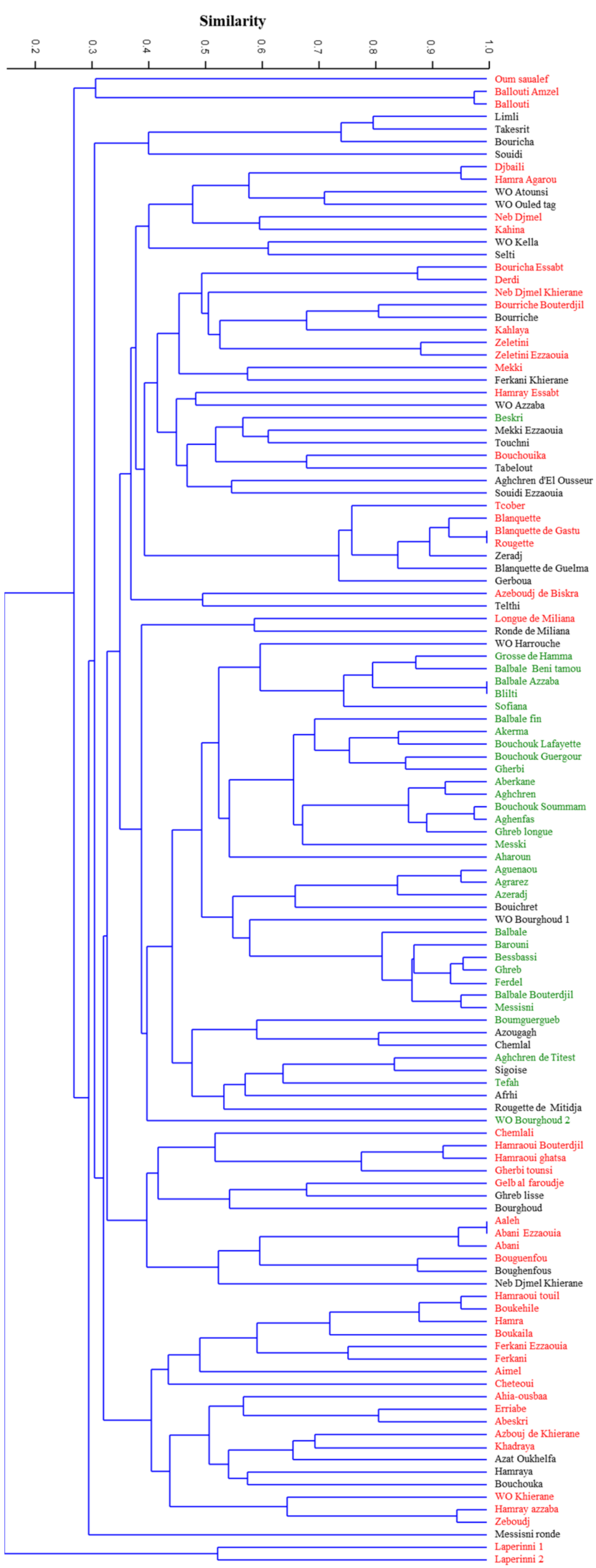

Figure 1. Dendrogram of 119 Algerian olive accessions obtained with 12 SSR markers, based on the UPGMA methodology according to the Dice coefficient. Red and Green colors correspond to the two differentiate groups found by STRUCTURE analysis. Black color refers to admixed genotypes. 
Even though the Algerian accessions showed high genetic variability, several putative synonymy cases and/or strict relationships were observed among the following combinations of genotypes: 'Ballouti amzel' /'Ballouti', 'Djbaili'/'Hamra Agarou', 'Blanquette'/Blanquette de Gastu'/'Rougette', 'Balbale Azzaba'/'Blilti',' 'Bouchouk soummam' /'Aghenfans', 'Aguenanou' / Agrarez', 'Bessbassi' /'Ghreb' /'Ferdel', 'Balbal Bouterdjil' /'Messisni', 'Aeleh' /'Abani ezzaouia' /'Abani', 'Boukehile' /'Hamraoui touil', 'Hamray azzaba' /'Zeboudj'.

Genetic relationships among Algerian olive genotypes were highlighted also by using a Principal coordinate analysis (PCOA) that generated a total variation of $17.18 \%$ (Figure 2). The first and the second principal coordinates explained $10.43 \%$ and $6.75 \%$ of genetic variation, respectively. The axes distributed the 119 accessions into main groups following UPGMA clustering and presenting weak relationships. We observed two principal groups, in each main group clusters dispersed according to the type of fruit. The genotypes used as table olives and oil production were grouped into two separated group 1 and group 2, respectively.

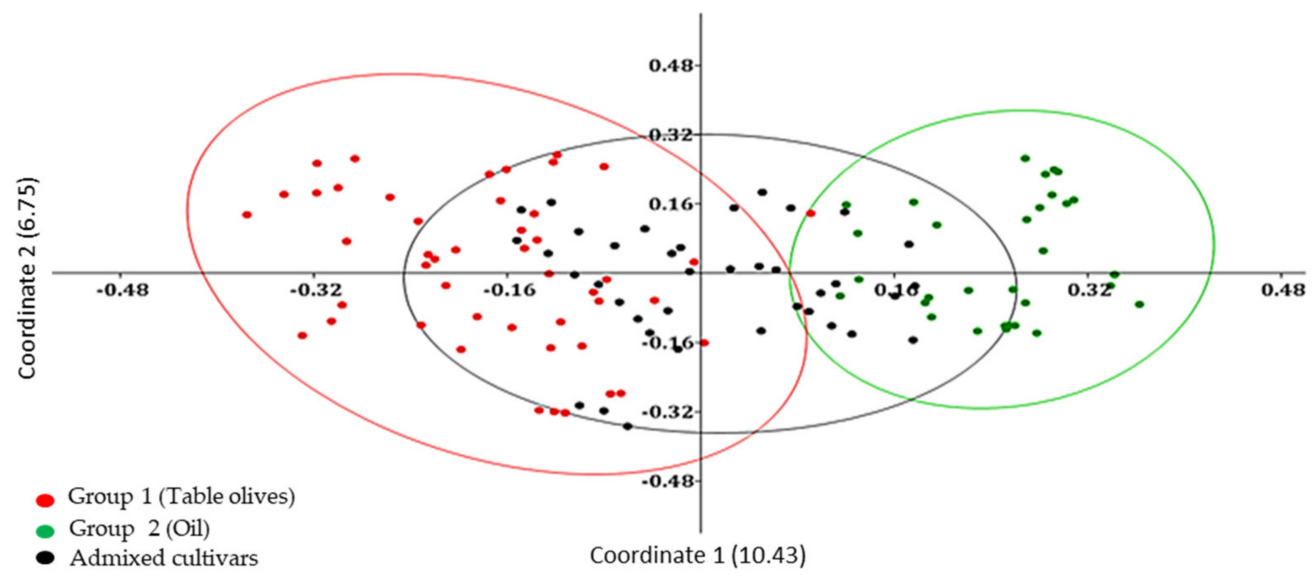

Figure 2. Principal Coordinates Analysis (PCoA) discriminating among 119 Algerian olive accessions based on use-destination.

\subsection{Population Structure and Molecular Variance Analysis}

Population structure was investigated using model-based Bayesian clustering applying STRUCTURE analysis without prior information. Olive tree accessions were grouped in two groups of distinct genetic pools $(\mathrm{K}=2)$ and several admixed accessions (Figure 3). Algerian accessions seemed to be grouped, according to the end use (oil or table) and the size of fruit as previously highlighted by both the UPGMA and PcoA cluster analysis. A threshold of $>80 \%$ membership q value was used for the designation of group representatives. The first group included 32 genotypes (table olive) and one putative wild accession (WO Bourghoud 2) characterized by a very high fruit size. The second group was composed of 49 genotypes used for oil production, 4 cultivars for double use ('Guelb al Feroudje', 'Tcober', 'Abeskri', 'Gherbi tounsi'), one wild putative accession (WO Khierane) and two accessions of subsp. laperrinei. The other 41 genotypes (33.6\%) were assigned to admixed genotypes. 


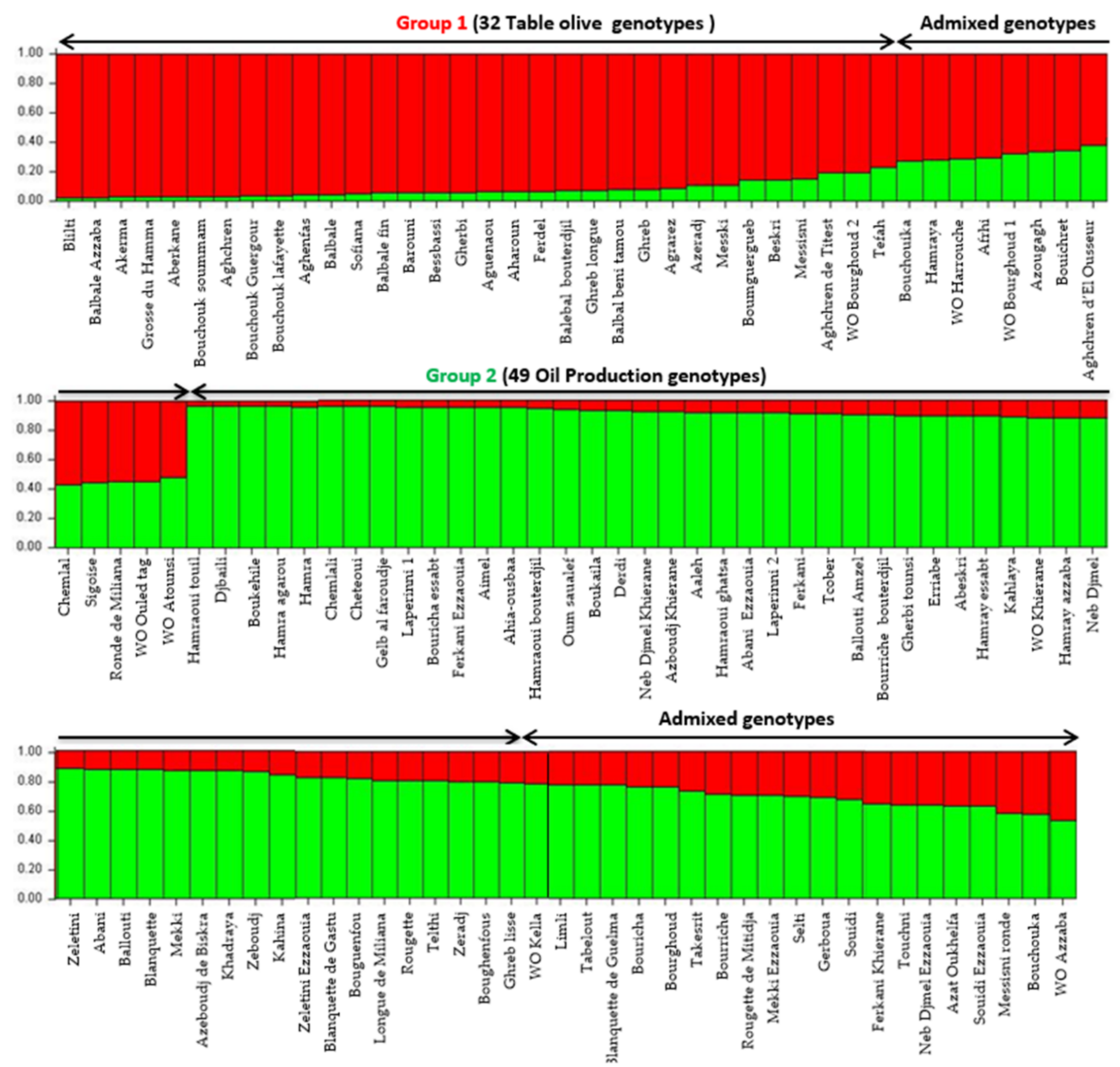

Figure 3. The genetic population structure of 119 Algerian genotypes identified by the STRUCTURE algorithm at $K=2$. The red bar includes the first group; the green bar includes the second group; admixed accessions include samples not assigned to a single group.

AMOVA was calculated between the two genetic groups according to structure analysis results (Table 2 ). The observed PhiPT value was highly statistically significant (Fst $=0.062$ ) when a random permutation value of 9999 was used indicating low-moderate genetic differentiation among the sub-populations tested. Most of the genetic variability could be explained by differences within individual referred to a whole population (89\%), while $5 \%$ and $6 \%$ of the total variance was observed within single sub-population and among sub-populations, respectively.

Table 2. Analysis of molecular variance (AMOVA) of 119 Algerian olive accessions.

\begin{tabular}{cccccccc}
\hline Source of Variance & DF & SS & MS & $\begin{array}{c}\text { Variance } \\
\text { Components }\end{array}$ & F-Statistics & $\begin{array}{c}\text { Total } \\
\text { Variation }\end{array}$ & $p$ \\
\hline Among Populations (Fst) & 2 & 57.087 & 28.543 & 0.298 & 0.062 & $6 \%$ & $<0.001$ \\
Within Population (Fis) & 119 & 560.708 & 4.712 & 0.235 & 0.052 & $5 \%$ & $<0.001$ \\
Within Individual (Fit) & 119 & 517.50 & 4.242 & 4.242 & 0.112 & $89 \%$ & $<0.001$ \\
\hline
\end{tabular}

\subsection{Algerian Accessions Relationships with the Central-Western Olive Germplasm}

A cluster analysis aimed to evaluate the occurrence of synonymy cases and highlight relationships among the Central-Western olive germplasm, was carried out on a sample of 461 individuals overall. Interestingly, new strict relationships characterized by very high 
similarity index were brought to light (Figure S1; Table S4). In this case, the dendrogram could also be divided in two main clusters with subsp. laperrinei included in a single group. All the other genotypes were included in the second cluster with several differentiated sub-groups. In general, Tunisian germplasm was found in almost all sub clusters.

In a first sub cluster, a relationship was found between the Sicilian variety 'Cerasuola' and the group belonging to the Tunisian variety 'Zarrazi' (Dice similarity index: 0.75-0.93) where the accession 'Sic_45' corresponded to the authenticated variety 'Zarrazi' held in the CREA-OFA collection. In the same sub cluster, the Spanish cultivar 'Morrut' clustered with a 'Chemlali' group belonging to Tunisian genotypes with a range of similarity beteen 0.7 to 0.82 . The accession 'Sic_22' was strictly related to the Tunisian accession 'Rkhami3' (0.87). Furthermore, the Algerian accessions 'Ferkani' /'Ferkani Ezzaouia'were really similar to the Tunisian genotypes 'Chemchali Gafsa' (0.93).

A second sub cluster included 19 Algerian accessions, the French cultivars' Picholine', 'Oliviere', 'Picholine di Languedoc' and 'Bouteillan' and the Spanish varieties 'Arbequina', 'Arbosana', 'Sabatera', Joanenca', and 'Perafort' and 8 Sicilian genotypes, three belonging to known cultivars ('Pidicuddara', Patrinostraru', 'Zaituna').

Another very large sub cluster included most of the Spanish varieties with a wide range of variability. Only 3 Algerian accessions were included in this sub cluster. Relationships were found between Sicilian and Spanish olive germplasm, such as between 'Pizzutella' and 'Ojo de Liebre' (0.76), 'Manzanilla de Jaen' (0.86), and the unknown accession 'Sic_33' and 'Dulzal' (1).

A really interesting sub cluster including 31 Algerian genotypes, 40 Sicilian genotypes, both accessions and known cultivars, and 3 Spanish varieties 'Manzanillo de Cabra,' 'Temprano' and 'Gordal Sevillana'. The latter Spanish variety showed strict relationships with the Sicilian varieties 'Pizzo di Corvo' /'Giarraffa' $(0.87,0.91)$ and the Algerian genotypes 'Balbale Fin', 'Blilti', and 'Grosse du Hamma' (0.82-1).

In a very 'mosaic' little subcluster we found Spanish, Algerian, Tunisian, and Sicilian germplasm where the Sicilian cultivar 'Nocellara del Belice' showed strict association with Tunisian genotypes. The Algerian accession 'Gelb al Faroudi' showed very high similarity with the Sicilian accession 'Sic_2' (0.94).

Also noteworthy was the substantial genetic uniformity detected between the Sicilian cultivar 'Sant'agatese' and the Spanish cultivar 'Cirujal' (1). The Algerian 'Messki' clustered strictly with the Tunisian accession named 'Meski' (0.97) and with the Spanish cultivar 'Fulla de Salze' (0.85).

A well differentiated sub cluster was found including mostly Algerian accessions, 2 Sicilian cultivars 'Minuta' (similar to 'Vaddara' and 'Monaca'), 'Mandanici' and 'Cacazzara'. Only one Spanish cultivar ('Empeltre') was found in this group. In this group, other strict relationships were also found among Algerian and Tunisian germplasm: 'Blanquette' /'Rougette' /'Sayali3' /'Chetoui' /'Zeradj' /'ChaibiOntha' /'Tcober' /'Blanquette de Guelma' /'Haouaria' and 'Gerboua' accessions with a variable range of similarity between 0.73 and 1.

Private alleles in the Algerian germplasm were further confirmed by comparison of molecular profiles with the accessions from Tunisia, Sicily, Spain and France (Table S2) except in one case. Interestingly, the $167 \mathrm{bp}$ allele at the locus GAPU 71b previously found exclusively in subsp. laperrinei was also detected in a few Spanish cultivars, such as the ancient variety 'Farga'.

\subsection{Population Structure of the Central-Western Olive Germplasm and Molecular Variance}

The genetic population structure analysis was conducted on the panel of olive tree accessions excluding putative synonym cases. The Bayesian clustering model implemented in STRUCTURE software indicated $\mathrm{K}=2$ as the best number of sub-populations (Figure S2) confirming substantially the dendrogram results. Two main groups were in fact highlighted with the most of Algerian samples included in the first group while the most of Spanish varieties were included in the second one. Admixed genotypes were assigned when 
membership value was less than $80 \%[2,18]$ and in according to this criterion, a rather high number of admixed genotypes were individuated. These results reflect the framework of genetic pattern of diversification of cultivated olive in the Mediterranean basin already previously described $[2,3,5]$ except for the 2 accessions of subsp. laperrinei which clustered in the same group of Algerian accessions. This latter group included in fact 48 accessions among Algerian cultivars, wild olives, and subsp. laperrinei. In the same group were included also 3 French cultivars ('Oliviere', 'Zinzala', and 'Picholine du Languedoc'), 17 known Sicilian varieties, 13 unknown Sicilian accessions, 12 Spanish cultivars among which the cultivars 'Arbequina', 'Empeltre', and 'Farga'. Furthermore 17 Tunisian genotypes were included in this group. The second group comprised 57 Spanish varieties and the only Moroccan variety included in the dataset while a much more reduced number of genotypes from Central Mediterranean basin were found in this group: 3 Sicilian varieties ('Giarraffa', 'Moresca', and 'Vallanella'), 3 Sicilian unknown accessions, and 3 Algerian varieties. No Tunisian genotypes belonged to this group. Admixed genotypes included most of Sicilian germplasm (49 accessions) both known cultivars (21) and unknown genotypes (28). Overall, 25 accessions clustered next to the 'Algerian group' showing a membership threshold slightly lower than $80 \%$ while 18 accessions shared most of their gene pool with the 'Spanish group'. However, it is worth to note a high admixture level was found for all the genotypes tested with different geographic provenience sharing most of their alleles with the 'Algerian group'.

Molecular variance analysis (AMOVA) was conducted on the two differentiated groups highlighted by STRUCTURE using the same previous described parameters. The observed PhiPT value was highly statistically significant $(\mathrm{Fst}=0.274)$ indicating high differentiation level between the two groups explaining $27 \%$ total variance. However, genetic variation within population explained most of the total variance (Table 3).

Table 3. Analysis of molecular variance (AMOVA) of the Central-Western Olive Germplasm.

\begin{tabular}{ccccccc}
\hline Source of Variance & DF & SS & MS & Variance Components & Total Variation & $p$ \\
\hline Among Populations (Fst) & 1 & 261.46 & 261.46 & 3.15 & $27 \%$ & 0.000 \\
Within Populations (Fis) & 164 & 1368.43 & 8.34 & 8.34 & $73 \%$ & 0.000 \\
\hline
\end{tabular}

\subsection{Diversification Process: Evidence of Bottleneck, Parentage Analysis, and Demographic Modelling}

Evidence for a bottleneck was evaluated using the genetic differentiated groups individuated by STRUCTURE analysis and here treated as two divergent populations. Three different tests were conducted to detect significant deviations from mutation-drift equilibrium but no significant excess of heterozygosity was detected under one-tailed Wilcoxon rank test. As described above, the two genetic groups did not reflect completely geographic localization of the genotypes here analyzed. In order to evaluate a putative 'geographic effect' and infer new hypothesis about diversification process of cultivated olive in the Mediterranean basin, we tried to evaluate bottleneck on dataset including only Spanish and Algerian varieties differentiated by Structure analysis. No evidence of signature for a bottleneck was found in Algerian population while a significant deviation from mutation-drift equilibrium was observed for the sample of 57 Spanish varieties included in the dataset $(p=0.027)$ confirming results obtained by Diez et al. [2]. Parentage analysis conducted on the whole dataset from the Central-Western Mediterranean basin (without putative synonyms) as candidate parents (324) revealed critical LOD scores of 17.77 and 13.08 for the parent pair analysis with unknown sexes for strict $(95 \%)$ and relaxed $(80 \%)$ confidence levels, respectively. The main putative pairs of parents, without mismatch between loci are shown in Table S5. Several Algerian accessions were included in offspring combinations with genotypes from all the geographic proveniences. The Algerian accessions 'Bouchouk Guergour', 'Mekki Ezzaouia,' 'Bouchouika', 'Sofiana', 'Aghenfas', were more frequently detected in offspring combinations. Spanish germplasm was also involved in several 
offspring combinations with genotypes of different provenience, in particular the varieties 'Limoncillo', 'Redondilla de Logroño', 'Escarabajuelo de Atarfe', 'Escarabajuelo de Posadas', 'Manzanilla de Abla', 'Habichuelero de Grazalema', 'Alfafara'. More in general, higher number of 'Spanish' offspring combinations were detected, confirming the bottleneck event as favoring the allele fixation in the Spanish population.

Sicilian varieties such as 'Giarraffa', 'Pizzutella', and 'Sant'agatese' were also included in several offspring combinations. The 'Giarraffa' being really genetically similar to the Spanish cultivar 'Gordal Sevillana' was included in offspring combinations with several Spanish cultivars and this is an aspect that can mislead the results on the genetic relationships between olive varieties, highlighting the importance to identify potential cases of synonymy for a correct interpretation.

However, also 'Pizzutella' matched with several Spanish and Algerian varieties. Strict relationships with Spanish germplasm were found also for 'Sant'agatese' belonging to the 'Algerian group' from the structure analysis. Interestingly the old Spanish variety 'Farga' was included in this offspring combination. Several unknown Sicilian accessions showed know Sicilian cultivars as putative parentals, but in a few cases also varieties from other proveniences confirming Sicily as a region really rich in olive trees biodiversity due to its geographical position in the center of the Mediterranean which has favored the passage of many civilizations. The French varieties here considered showed offspring combinations with different provenience genotypes.

In this work we did not have different samples of wild olive accessions available to build a scenario able to elucidate domestication process but we decided to evaluate the best fitting demographic model with observed data using Approximate Bayesian Computation $(A B C)$ in order to clarify the diversification process of cultivated olive around the Central-Western Mediterranean basin. Considering the results obtained on the diversity and genetic structure of the Algerian population per se and compared with the germplasm of the Central-Western Mediterranean basin as well as the hypothesis still open on domestication centers, we defined 4 historical scenarios using subsp. laperrinei as common ancestral lineage although a low number of samples were available (Figure S3). To simplify completely the model, we used a dataset with differentiated populations by STRUCTURE analysis coming from Algeria and Spain exclusively and their admixed accessions. In the scenarios definition we considered both divergence and admixture events (Figure S3). Since, in general, every population divergence event is followed by a bottleneck, the ABC asks to include this kind of event. Because of long generation time of olive tree, we assumed a generation time of 20 years as indicated by Diez et al. [2]. All the parameters of the historical models were described in Figure S3. The posterior probabilities of scenario were computed by local linear regression using the 10 subsets of simulated data closest to observed data. The results showed for all the 10 subsets of data a $99 \%$ confidence interval for the scenario 1 indicating this scenario was the best supported by observed data (Figure 4). We also evaluated the posterior error rate given as a proportion of wrongly identified scenarios over the 1000 test data sets for both the direct and the logistic approaches. The global prior error rate for scenario 1 was 0.38 . We also evaluated the prior error rate for a specific scenario that allows to estimate two type of errors: type I error which is the probability to reject the true scenario and type II error that indicates the probability to accept a wrong scenario. The probabilities to commit both the I and II error type were very low, ranging from 1.7 to $2.6 \%$ and from 4.9 to $5.5 \%$, respectively, considering each specific scenario. 


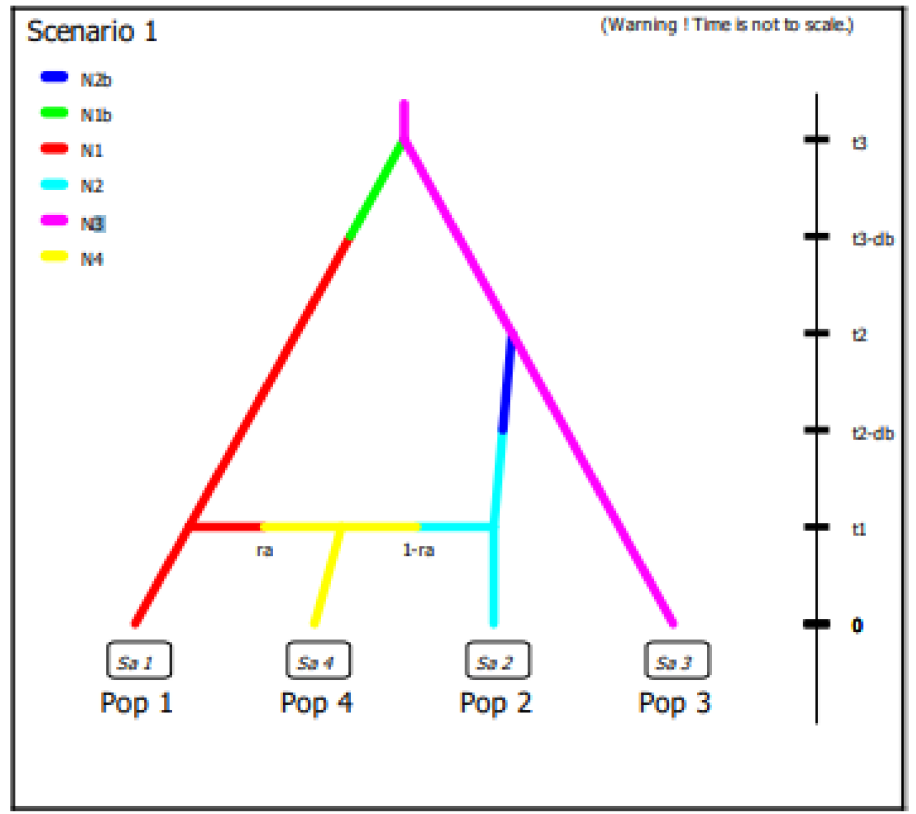

Figure 4. The best supported scenario by the observed data calculated using ABC. In this scenario an independent origin of Pop1 was hypothesized (Algeria sample) and Pop 2 (Spanish sample) and one recent admixture event (Pop 4) with 70\% rate of admixture (ra) from Pop1 Historical parameters: $\mathrm{t} 3$ : 300; t2: 280; db: 50; t1: 88; N1: 47; N2: 57; N3: 2; N4: 74; ra: 0.7, N1b: 40, N2b: 50.

\section{Discussion}

The first purpose of this work was to improve knowledge on the genetic diversity and population structure of Algerian olive germplasm. For this aim, a set of 12 SSR markers was used for genotyping of 109 cultivars, 8 putative wild (or feral) accessions and 2 individuals belonging to subsp. laperrinei. The average number of alleles here observed was higher than those obtained in previous works [15,19]. The expected and observed heterozygosity averages in our study were higher $[1,12]$ or comparable $[10,20]$ with those observed in previous works aimed to Algerian olive germplasm genotyping. These results confirmed the high genetic variability of Algerian olive germplasm. Based on the Polymorphism Index Content (PIC) and Shannon's information index (I) values, we could classify the used primers according to their effectiveness. The most suitable loci for the genetic characterization for the analyzed genotypes were DCA 18, DCA 3, and DCA 8 , which showed polymorphism equal to or higher than $80 \%$ and Shannon's information index more than 2, results in accordance with previous studies [11,21]. Among the 127 alleles found in genotyping of the Algerian accessions, a consistent number of private alleles was detected indicating that a putative isolation process might have occurred. For instance, several private alleles were detected in the subsp. laperrinei, one of the first subsp. of the Olea complex that has differentiated following successive phases of aridification of the Saharan region since the Late Miocene [3]. Cluster analysis in our study confirmed an early differentiation, in line with previous studies which clearly indicated phenotypic and genetic divergence between subsp. laperrinei and cultivated olive (subsp. europaea var. bot. europaea), while maintaining the interfertility $[4,8,22]$. However, cluster, PCoA and genetic structure population analysis did not detect a grouping related to geographical location for cultivated and putative wild (or feral) olive trees, but the clustering seemed to be related mostly to the fruit end-use, in accordance with the previous results obtained by AFLP, RAPD, and SNP markers [23-25]. AMOVA analysis indicated further a weak differentiation structure detected in our set of analyzed samples. A low Fst value was expected due to the lack of geographical discrimination observed and large distribution of genetic variability detected between cultivated and putative wild (or feral) olives. 
Our results highlighted several groups of synonyms and homonymies, probably due the widest sample ever collected before for Algerian germplasm characterization. In this study, 46 accessions (including two accessions of subps. laperrinei) from ITAFV official Algerian collections were analyzed giving new molecular information for further 10 cultivars ('Aghchren', 'Azeboudj de Biskra', 'Azougagh', 'Balbal Beni tamou', 'Blanquette', 'Boumguergueb', 'Gerboua', 'Rougette', 'Zeboudj', 'Zeletini'). In Algeria, the nomenclature of olive cultivars occurs in different languages (Arabic, Berbere) and mainly refers to several traits such as the color (Aberkane, Suidi, and Kahlaya for black olives; Azougagh, Hamra, and Hamray for red olives), surface and size of leaves (Bouricha, Bourriche for cultivars with large size leaves), the ripening period (Chetoui in winter and Tcober in October) and their origin (Zeboudj and Azeboudj for wild olive). Because of the long history of cultivation and absence of a common criteria for cultivar classification, these indigenous names may have contributed to the confusion in the varieties cataloguing. Cluster analysis highlighted putative synonymies such as the case of the cultivars 'Aaleh' (also named 'Aeleh' or 'Aeleth'), 'Abani' and the accession 'Abani Ezzaouia.' This result was confirmed also by a previous work [20]. The 'Aaleh' and 'Abani' cultivars are currently held in the ITAFV collection in Bejaia. However, our results lead us to speculate the 'Aaleh' variety held in ITAFV could be not authentic, because the 'Aeleh' variety was in the past described as a plant originally from Bejaia, with small-rounded olives grouped at the base of the twigs [26] whereas the 'Aaleh' variety from ITAFV collection was collected in Chechar Khenchela district and morphologically described with elongated fruits, really similar to 'Abani' cultivar [9]. Lastly, within an internal survey conducted with local farmers in Khenchela, the 'Aaleh' name was never mentioned (Personal communication). The inter varietal discrimination among accessions from ITAFV of Bejaia and their molecular profiles obtained in this study only partially agree with those of previous works [1,10-12,20], raising the doubt that there is still some confusion in the management of Algerian germplasm and highlighting that varietal authentication processes are still very necessary.

The dendrogram showed near-synonyms cases whose allelic profiles differed at $\leq 2$ loci. Previous studies explained these slight differences probably due to spontaneous somatic mutations reported as a frequent event in long-lived olive trees propagated by cloning [27-29]. In addition, we observed twelve cases of homonymies involving the following cultivars: 'Ferkani', 'Neb Djmel', 'Mekki', 'Souidi', 'Zeletini', 'Bouricha', 'Hamray', 'Balbale', 'Bourriche', 'Hamra', and 'Hamraoui' collected from different locations (ITAFV collections, Skikda, Khenchela, and Mila). More than one accession shared the same basic name but the dendogram clearly showed their genetic diversity. These cases of homonymy in Algerian germplasm included most cultivars maintained in situ and never characterized before, except a few minor accessions previously reported [10,12,30].

Ancient fossil studies in North Africa [31,32] have mentioned that the wild olive had existed in many Saharan sites much earlier than the 12th millennium BC [32]. Therefore, a domestication event is likely to have occurred in the Auras region with further spread of the olive tree grown in the rest of Algeria. We found a close relationship between different varieties from the Auras region which includes the provinces of Batna, Biskra, Tebessa, and Khenchela. These cultivars belong to two subgroups in the dendrogram and the same STRUCTURE group, showing the same end-use. In the Auras region, olive groves have remained confined along the valleys and mountainous areas and this region is witnessing a significant decline in genetic resources due to environmental changes. Varieties from this region have adapted to difficult environmental factors, such as high temperatures, and should be considered an attractive genetic resource for adaptive traits. Accessions from Auras region were clustered in a differentiated group (i.e., 'Erriabe', 'Abeskri', 'Azeboudj Khierane', etc.) showing similar end-use. Relationships were due to the geographical isolation which gave rise to admixed genotypes only in a few cases. Phylogenetic analysis here conducted were consistent with the previous fossil studies [31,32] led us to hypothesize an ancient origin for this group of varieties. 
In this study, no clear distinction was observed between cultivated and putative wild olives in agreement with other previous studies [33,34]. New genuine olive accessions were here included in the Algerian olive germplasm biodiversity.

Likewise, to provide new insights about the olive diversification history and other evolutionary events in the Central-Western Mediterranean basin, Algerian germplasm was compared with other cultivars and accessions from the Central-Western Mediterranean basin. The dendrogram and structure analysis showed a differentiation of the CentralWestern Mediterranean olive germplasm in two groups: the group of Spanish varieties which exhibited a characteristic bottleneck and the 'Algerian' germplasm which includes the greater part of the Mediterranean germplasm analyzed here.

High admixture rate was observed especially for Sicilian germplasm sharing most of 'Algerian' gene pool. These results confirmed the pattern of diversification of cultivated olive germplasm and bottleneck evidence previously described [2]. The 'Algerian' genepool of this study could be referred to group Q2 while the 'Spanish' germplasm could be referred to $\mathrm{Q} 1[2,5]$.

In this case, cluster analysis conducted among Algerian olive germplasm and other cultivars and accessions from the Central-Western Mediterranean basin also highlighted a clear differentiation of susp. laperrinei. However, structure analysis included the accessions belonging to this subsp. in the same group of the 'Algerian' germplasm. Haddad et al. [1] found the highest proportion of Algerian varieties shared the same haplotype with the majority of Mediterranean cultivars (clorotype E1) and the Laperrine's olive, speculating about a local domestication process from oleasters and this subspecies. Besnard et al. [2] found a plastidic lineage shared among cultivated and Laperrine's olive not present in oleaster. Most of the private alleles previously found in the Algerian germplasm were not found in the rest of Mediterranean germplasm while a few of them and some rare alleles were found almost exclusively in Mediterranean germplasm belonging to 'Algerian group' and some admixed genotypes sharing most of 'Algerian' alleles. The two 'Laperrinei' accessions carry mutations that were fixed in the population and maintained as result of ancient isolation, resulting in private alleles. However, in one case, the allele $167 \mathrm{bp}$ at the locus DCA18 was detected in 6 Spanish varieties sharing the 'Algerian' gene pool as in the very old cultivar 'Farga'. The presence of the $167 \mathrm{bp}$ allele found exclusively in these Spanish varieties led us to consider a different temporal and spatial origin of Spanish germplasm.

Cluster analysis highlighted several cases of putative synonymy leading us to speculate about the path of diffusion of important traditional cultivars such as 'Giarraffa' and 'Gordal Sevillana' from Sicily and Spain, respectively, by vegetative propagation. In this study we found out a new strict relationship of these cultivars with Algerian genotypes such as 'Balbale Fin', 'Blilti', and 'Grosse du Hamma' belonging to 'Spanish' groups as showed by STRUCTURE analysis. The parentage analysis included 'Giarraffa' in several offspring combinations without mismatches with a few Sicilian, Tunisian and Spanish accessions/cultivars. Diez et al. [2] indicated the old cultivar 'Gordal Sevillana' as putative parental line of modern Spanish cultivars. Afterwards, more recent admixture events occurred giving rise to admixed cultivars such as 'Moresca', 'Lumiaru', 'Ogliarola Messinese', and other unknown Sicilian accessions here analyzed. In Algeria we found the 'Blilti' genotype as putative parental line of the 'WO Harrouche'. The Algerian variety 'Sofiana' with strict relationships with 'Gordal Sevillana' /'Giarraffa' could be a putative parental line of admixed varieties such as 'Lumiaru' and 'Bouchouika'. We hypothesized that the Spanish variety 'Gordal Sevillana' was spread by vegetative propagation along the southern coasts of the Mediterranean, until reaching Algeria and Sicily.

Most of synonymy cases for Algerian germplasm were found with Tunisian genotypes. A relatively low number of Tunisian alleles were included in the analysis but it is reasonable to assume that an active exchange of vegetatively propagated material probably took place due to the closeness of these two countries. 
The demographic analysis confirmed our hypothesis: the best supported model was the scenario where we hypothesized an independent origin of Algerian and Spanish populations from each other and where recently they gave origin by a 'mosaic' (admixture) population. Furthermore, in this model we set up a more recent origin for the Spanish population than the Algerian germplasm. Diez et al. [2] observed that the Spanish group Q1 derived from a more recent admixture event between wild east (WE) and wild west (WW) oleasters while Q2 seemed to have diversified earlier and originated from Q3 and WW. Although, we had neither wild olive population nor cultivated olive accessions from East Mediterranean area available for inferring historical and genetic evolution of cultivated olive, our results seem to confirm an independent evolution of Algerian and Spanish populations. The admixed population here found by structure analysis showed a recent origin consistent with the 'mosaic' population described by Diez et al. [2]. Admixture events probably occurred by historical migrations during the existence of ancient Maghreb. In fact, our study included cultivars and accessions from Algeria, Tunisia, Morocco, Sicilia, Spain (formerly defined El-Andalus), and France, countries that historically concurred to form the ancient Maghreb. Furthermore, we hypothesize that the spreading of 'Gordal Sevillana' towards Sicily and Algeria, giving rise to local admixed varieties and accessions, could be due to the more recent Islamic invasion.

On the other hand, the STRUCTURE analysis included some Spanish varieties within the 'Algerian' group such as the ancient 'Farga' variety and the 'Cirujal' cultivar genetically very similar to the Sicilian 'Sant'Agatese' cultivar. Diez et al. [2] found the 'Cirujal' cultivar in the Q3 group, including the eastern cultivars and from which the Q2 group originated. Our results seem to confirm an early diversification of the 'Algerian' gene pool probably widely spread by the Phoenicians along the African and Sicilian coasts starting from the Levant.

The large diffusion of the 'Algerian' gene pool throughout the Central Mediterranean countries here found corroborates the hypothesis a very early diversification process might have occurred.

\section{Materials and Methods}

\subsection{Plant Material}

In this work, 119 Algerian olive tree accessions including 109 cultivated varieties, 8 putative wild (or feral) olive trees (WO), and 2 accessions of Olea europaea subsp. laperrinei were collected and georeferenced (Table S3; Figure 5). Among the cultivated olive varieties, 44 accessions were obtained from the National Germplasm collections held at the Institut de l'Arboricolture Fruitiére et de la Vigne (ITAFV) located in several cities: 35 varieties were collected from Béjaia Tekerietz, 8 varieties from Blida (Beni Tamou), 1 variety from Constantine (El Hama), while 2 accessions belonging to the sub-sp. laperrinei were collected from Alger (Tassala elmerdja). The other 76 local accessions (cultivated and WO accessions) were collected in situ both in natural sites and private orchards. The sampling was conducted using different geographical distribution as criteria in the eastern Algeria: 8 accessions from Batna, 1 from Bejaia, 20 accessions, and 1 WO tree from Khenchela, 21 accessions and 5 WO trees from Tassadane Mila, 12 accessions and 2 WO trees from El harrouche Skikda, and 6 accessions from Souk Ahras. A population of 52 Sicilian unknown accessions and a set of 51 reference Sicilian varieties were included in the analysis (Table S2) for the comparison between Algerian samples and the olive germplasm from Central-Western Mediterranean Basin. The Sicilian varieties were collected at the Council for Agricultural Research and Economics-Research Center for Olive, Fruit and Citrus Crops (CREA-OFA) varietal collection field located in Mirto, on the Ionian coast of the province of Cosenza, Italy. The unknown accessions were collected under different geographical locations in Sicily region. 


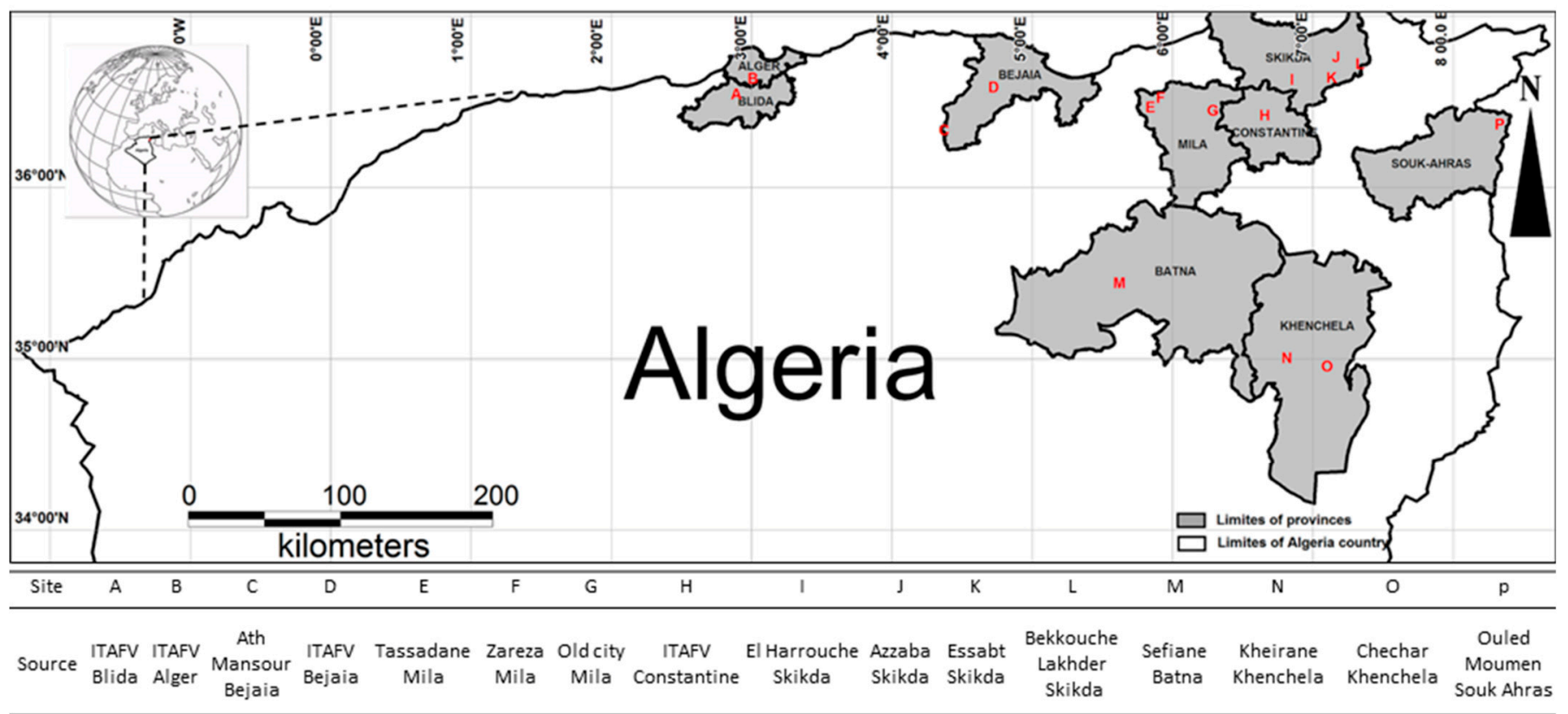

Figure 5. Map of geographical distribution of collected Algerian samples in this study.

\subsection{DNA Extraction}

Genomic DNA was extracted from $50 \mathrm{mg}$ finely ground powder of young leaves using a commercial kit (Plant DNA Mini Kit, Qiagen, Hilden, Germany). DNA quality and concentration were checked with a NanoDrop 2000 spectrophotometer (Thermo Scientific, Waltham, MA, USA), diluted to $20 \mathrm{ng} / \mu \mathrm{L}$ and stored at $-20{ }^{\circ} \mathrm{C}$ until used.

\subsection{Microsatellite Analysis}

The following twelve labelled microsatellite markers (SSR) were selected and used for molecular analysis in 4 multiplex combinations: DCA3-6FAM, DCA5-VIC, DCA8-VIC, DCA11-PET, DCA18-6FAM [35], EMO90-NED [13], GAPU71b-6FAM [36], OLEST7-PET, OLEST14-VIC, OLEST23-PET [37], and UDO12-NED, UDO15-NED [27] (Table S6). These microsatellite markers were chosen according to their level of polymorphism degree in Algerian olive trees [1,10,12,30], reproducibility, ease of reading and suitability for multiplex amplification strategy [21]. Amplification by PCR for all the multiplex combinations was carried out in a total volume of $15 \mu \mathrm{L}$, containing $10 \mathrm{ng}$ of genomic DNA, 10× PCR buffer, $2 \mathrm{mM} \mathrm{MgCl} 2,2.5 \mathrm{mM}$ dNTPs, $10 \mu \mathrm{M}$ of forward and reverse primers, and $5 \mathrm{U} / \mu \mathrm{L}$ Taq polymerase, using a thermal cycler (GeneAmp PCR System 9700 Applied Biosystems Inc., Foster City, CA, USA). The PCR thermal profile was programmed as follows: a first step at $94{ }^{\circ} \mathrm{C}$ for $5 \mathrm{~min}, 30$ cycles at $94{ }^{\circ} \mathrm{C}$ for $30 \mathrm{~s}, 55^{\circ} \mathrm{C}$ for $30 \mathrm{~s}$, and $72{ }^{\circ} \mathrm{C}$ for $40 \mathrm{~s}$. The last step included $7 \mathrm{~min}$ of incubation at $72{ }^{\circ} \mathrm{C}$. We also included two reference varieties (Leccino and Frantoio) in PCR amplification to check experimental conditions (data not shown). The GeneScan 500LIZ (Life Technologies, Carlsbad, CA, USA) was used as internal standard and the SSR migration was carried out using the Applied Biosystems SeqStudio Genetic Analyzer (Thermo Fisher Scientific Inc., Waltham, MA, USA).

\subsection{Data Analysis}

The amplified peaks were analyzed using the Gene Mapper v.6.0 software. In order to get a more complete framework of olive relationships in the Central-Western Mediterranean basin, molecular data results from Algerian and Sicilian samples were compared with 154, 74, 10, and 1 molecular profiles of cultivars from Spain, Tunisia, France, and Morocco, respectively, using common markers found in literature [18,38-40] in a range from 4 to 8 loci, and included in our internal database of the Council for Agricultural Research 
and Economics-Research Center for Olive, Fruit, and Citrus Crops (CREA-OFA). Before comparison, all SSR markers were subjected to a "binning" following the methodology described by Ben Mohamed et al. [39]. For each locus SSR, the alleles detected were scored as present (1) or absent (0), then a similarity matrix using Dice's coefficient [41] was first obtained and used to determine the cluster analysis based on the unweighted pair group method with arithmetic mean (UPGMA). A dendrogram and cophenetic correlations were obtained using Past software v.2.12.

To avoid considering variants of the same accession in the data analyses but also to avoid including families of very closely related individuals that can bias Bayesian clustering analyses [42], we decided to keep the molecular profile of known reference cultivars or in the case of accessions we chose randomly only one tree for such closely related accessions. Then, all genetic diversity and structure population analysis were carried out on a sample of individuals considered to have a unique profile.

The number of alleles per locus (A), their frequency (Fa), observed (Ho), and expected heterozygosity $(\mathrm{He})$, polymorphism information content (PIC), were calculated using Cervus v.3.0.7 [43]. The Wright's inbreeding coefficient (Fis), the fixation index (Fst), the number of null alleles (F null), and the deviation from the Hardy-Weinberg equilibrium (HW) corrected using the Bonferroni method for each microsatellite locus and gene flow (Nm) estimates were calculated using PopGene software v.1.32 [44]. Shannon's information index (I) and the Analysis of Molecular Variance (AMOVA) were calculated using GenAlEx 6.5 using 9999 random permutations [45]. Analysis of the genetic structure populations was performed using a classification method based on a Bayesian model implemented in STRUCTURE v.2.3.4. software [46]. The admixture model with correlated allele frequency and a burn-in length of 100,000 followed by 100,000 runs at each K with three iterations for every K were used, with K ranging from 1 to 12. Then, the Structure Harvester web version 0.6.93 [47] was used to select the optimal $K$, using $\Delta \mathrm{K}$, according to Evanno et al. [48].

A test for evaluation of signature of genetic bottleneck was conducted using Bottleneck v.1.2.02, under the two-phase mutation model (T.P.M.) setting up 70\% stepwise mutations and a variance among multiple steps of 12 .

Relatedness between individuals was evaluated using a parentage analysis computed using Cervus v.3.0.7 software. An approach based on the logarithm of the odds (LOD) score significance was adopted and the following parameters were run: (i) number of offspring: 200,000; (ii) number of candidate parents: 324; (iii) proportion of candidate parents sampled: 0.7 ; (iv) proportion of loci typed: 0.8218. Default values were adopted for the parameters "proportion of loci mistyped" and "error rate in likelihood calculations". The relaxed and strict confidence levels were set up to $80 \%$ and to $95 \%$, respectively.

An Approximate Bayesian Computation (ABC) with DIYABC software v 2. [49] was used to compare possible scenarios for the same data file through the computation of the posterior probabilities of each scenario. For the ABC simulations of scenarios, a generalized stepwise model (GSM) is adopted where historical and mutational parameters are used to build each scenario. Mutational parameters refer to the mean mutation rate $(\mu)$ and the mean parameter $(\mathrm{P})$ of the geometric distribution with the aim to model the length of mutation events. In this work, we adopted the same mutational parameters and summary statistics indicated by Diez et al. [2], maintaining the allele range state for each locus as a default range (40) for all the SSR loci included in the model.

\section{Conclusions}

In this work we characterized new genetic resources from Algeria which enlarges the olive gene pool. Climate change severely affects the Mediterranean olive growing and new adaptative traits are needed to afford the challenge. A further effort will be needed to evaluate the Algerian germplasm as potentially source of genes encoding adaptative traits for facing olive growing new challenges. The comparison among Algerian olive germplasm and other cultivars and accessions from the Central-Western Mediterranean basin, highlighted new several cases and close relationships among accessions raising a 
new insight about the importance of vegetative propagation in the olive tree diffusion process along the Mediterranean basin. Demographic analysis corroborated the previous hypothesis of an early differentiation of olive germplasm from Central Mediterranean basin and recent admixture events occurrence confirming the high genetic variability present in the Central Mediterranean area, particularly in the Sicily region. These studies are crucial steps to address the retrieval of genetic resources and begin new pre-breeding activities.

Supplementary Materials: The following are available online at https://www.mdpi.com/article/ 10.3390/plants10040678/s1, Figure S1. Dendogram of the Central-Western Mediterranean accessions based on the UPGMA methodology; Figure S2. Structure analysis of the Central-Western Mediterranean olive accessions; Figure S3. The 4 scenarios compared using approximative Bayesian computation; Table S1. Size and frequency of alleles for the 12 SSR loci detected in the 119 olive accessions. In bold are shown private alleles; Table S2. Molecular profiles of the Central-Western Mediterranean olive accessions; Table S3. List of olive accessions collected, geographical origin, georeferentiation and use destination; Table S4. Dice similarity indexes among the 461 olive accessions from Central-Western Mediterranean basin; Table S5. Parentage analysis among Central-Western Mediterranean accessions; Table S6. Primers list, repeat motives, annealing temperature (Ta) and size range for the 12 SSR used for the genotyping of Algerian cultivars.

Author Contributions: Conceptualization, S.Z. and K.A.; methodology, K.A., S.Z., F.L.C., B.P.; software, S.Z. and K.A.; formal analysis, S.Z. and K.A.; investigation, S.Z. and K.A; resources, R.B., H.H., F.P.M. and F.L.C.; data curation, S.Z., K.A. and H.H.; writing-original draft preparation, S.Z. and K.A.; writing-review and editing, S.Z., K.A., R.B., A.S., F.P.M., A.M., F.L.C. and B.P.; funding acquisition, R.B. and S.Z. supervision: R.B. All authors have read and agreed to the published version of the manuscript.

Funding: This research received no external funding.

Institutional Review Board Statement: Not applicable.

Informed Consent Statement: Not applicable.

Acknowledgments: This work was supported by the Ministry of Higher Education and Scientific Research of Algeria and CREA-Centro di ricerca olivicoltura, frutticoltura, agrumicoltura Contrada Lì Rocchi Rende (CS) (Italy). We thank the both institutions for their assistance.

Conflicts of Interest: The authors declare no conflict of interest.

\section{References}

1. Haddad, B.; Gristina, A.S.; Mercati, F.; Saadi, A.E.; Aiter, N.; Martorana, A.; Carimi, F. Molecular Analysis of the Official Algerian Olive Collection Highlighted a Hotspot of Biodiversity in the Central Mediterranean Basin. Genes 2020, 11, 303. [CrossRef]

2. Diez, C.M.; Trujillo, I.; Martinez-Urdiroz, N.; Barranco, D.; Rallo, L.; Marfil, P.; Gaut, B.S. Olive domestication and diversification in the Mediterranean Basin. New Phytol. 2015, 206, 436-447. [CrossRef]

3. Besnard, G.; Terra, J.F.; Cornille, A. On the origins and domestication of the olive: A review and perspectives. Ann. Bot. 2018, 121, 385-403. [CrossRef]

4. Besnard, G.; Rubio de Casas, R.; Vargas, P. Plastid and nuclear DNA polymorphism reveals historical processes of isolation and reticulation in the olive tree complex (Olea europaea). J. Biogeogr. 2007, 4, 736-752. [CrossRef]

5. Besnard, G.; El Bakkali, A.; Haouane, H.; Baali-Cherif, D.; Moukhli, D.; Khadari, B. Population genetics of Mediterranean and Saharan olives: Geographic patterns of differentiation and evidence for early generations of admixture. Ann. Bot. 2013, 112, 1293-1302. [CrossRef] [PubMed]

6. Zohary, D.; Spiegel-Roy, P. Beginnings of fruit growing in the Old World. Science 1975, 187, 319-327. [CrossRef] [PubMed]

7. Kaniewski, D.; Van Campo, E.; Boiy, T.; Khadari, B.; Besnard, G. Primary domestication and early uses of the emblematic olive tree: Palaeobotanical, historical and molecular evidence from the Middle East. Biol. Rev. 2012, 87, 885-899. [CrossRef] [PubMed]

8. Besnard, G.; Anthelme, F.; Baali-Cherif, D. The Laperrine's olive tree (Oleaceae): A wild genetic resource of the cultivated olive and a model-species for studying the bi-ogeography of the Saharan Mountains. Acta Bot. Gall. 2012, 159, 319-328. [CrossRef]

9. Mendil, M.; Sebai, A. Catalogue des Variétés Algériennes de L'olivier; Ministère de L'agriculture et du Développement Rural, ITAF Alger: Tessala El Merdja, Algeria, 2006; p. 98.

10. Boucheffa, S.; Miazzi, M.; di Rienzo, V.; Mangini, G.; Fanelli, V.; Tamendjari, A.; Pignone, D.; Montemurro, C. The coexistence of oleaster and traditional varieties affects genetic diversity and population structure in Algerian olive (Olea europaea) germplasm. Genet. Resour. Crop. Evol. 2017, 64, 379-390. [CrossRef] 
11. Di Rienzo, V.; Sion, S.; Taranto, F.; D’Agostino, N.; Montemurro, C.; Fanelli, V.; Zammit-Mangion, M. Genetic flow among olive populations within the Mediterranean basin. Peer] 2018, 6, 5260. [CrossRef] [PubMed]

12. Abdessemed, S.; Muzzalupo, I.; Benbouza, H. Assessment of genetic diversity among Algerian olive (Olea europaea L.) cultivars using SSR marker. Sci. Hortic. 2015, 192, 10-20. [CrossRef]

13. De La Rosa, R.; James, C.M.; Tobutt, K.R. Isolation and characterization of polymorphic microsatellites in olive (Olea europaea L.) and their transferability to other genera in the Oleaceae. Mol. Ecol. Notes 2002, 2, 265-267. [CrossRef]

14. La Malfa, S.; Currò, S.; Douglas, A.B.; Brugaletta, M.; Caruso, M.; Gentile, A. Genetic diversity revealed by EST-SSR markers in carob tree (Ceratonia siliqua L.). Biochem. Syst. Ecol. 2014, 55, 205-211. [CrossRef]

15. Muzzalupo, I.; Vendramin, G.G.; Chiappetta, A. Genetic biodiversity of Italian olives (Olea europaea) germplasm analyzed by SSR markers. Sci. World J. 2014, 2014, 296590. [CrossRef]

16. Ulanovsky, S.; Gogorcena, Y.; de Toda, F.M.; Ortiz, J.M. Use of molecular markers in detection of synonymies and homonymies in grapevines (Vitis vinifera L.). Sci. Hortic. 2002, 92, 241-254. [CrossRef]

17. This, P.; Jung, A.; Boccacci, P.; Borrego, J.; Botta, R.; Costantini, L.; Crespan, M.; Dangl, G.S.; Eisenheld, C.; Ferreira-Monteiro, F.; et al. Development of a standard set of microsatellite reference alleles for identification of grape cultivars. Theor. Appl. Genet. 2004, 109, 1448-1458. [CrossRef] [PubMed]

18. Debbabi, O.M.; Miazzi, M.M.; Elloumi, O.; Fendri, M.F.; Ben Amar, F.; Savoia, M.; Sion, S.; Souabni, H.; Rahmani Mnasri, S.; Ben Abdelaali, S.; et al. Recovery, Assessment, and Molecular Characterization of Minor Olive Genotypes in Tunisia. Plants 2020, 9 , 382 .

19. Koehmstedt, A.M.; Aradhya, M.K.; Soleri, D.; Smith, J.L.; Polito, V.S. Molecular characterization of genetic diversity, structure, and differentiation in the olive (Olea europaea L.) germplasm collection of the United States Department of Agriculture. Genet. Res. Crop. Evol. 2011, 58, 519-531. [CrossRef]

20. Boucheffa, S.; Tamendjari, A.; Sanchez-Gimeno, A.C.; Rovellini, P.; Venturini, S.; Di Rienzo, V.; Miazzi, M.M.; Montemurro, C. Diversity Assessment of Algerian Wild and Cultivated Olives (Olea europaea L.) by Molecular, Morphological, and Chemical Traits. Eur. J. Lipid Sci. Technol. 2019, 121, 1800302.

21. Lombardo, L.; Fila, G.; Lombardo, N.; Epifani, C.; Duffy, D.H.; Godino, G.; Salimonti, A.; Zelasco, S. Uncovering olive biodi-versity through analysis of floral and fruiting biology and assessment of genetic diversity of 120 Italian cultivars with minor or marginal diffusion. Biology 2019, 8, 62. [CrossRef]

22. Baali-cherif, D.; Besnard, G. High genetic diversity and clonal growth in relict populations of Olea europaea subsp. laperrinei (Oleaceae) from Hoggar, Algeria. Ann. Bot. 2005, 96, 823-830. [CrossRef]

23. Besnard, G.; Baradat, P.; Bervillé, A. Genetic relationships in the olive (Olea europaea L.) reflect multilocal selection of cultivars. Theor. Appl. Genet. 2001, 102, 251-258. [CrossRef]

24. Grati-Kamoun, N.; Mahmoud, F.L.; Rebaï, A.; Gargouri, A.; Panaud, O.; Saar, A. Genetic diversity of Tunisian olive tree (Olea europaea L.) cultivars assessed by AFLP markers. Genet. Res. Crop. Evol. 2006, 53, 265-275. [CrossRef]

25. D'Agostino, N.; Taranto, F.; Camposeo, S.; Mangini, G.; Fanelli, V.; Gadaleta, S.; Di Rienzo, V.; Miazzi, M.M.; Pavan, S.; Lombardo, L.; et al. GBS-derived SNP catalogue unveiled genetic variability and geographical origin of Italian olive cultivars. Sci. Rep. 2018, 8,15877 . [CrossRef]

26. Trabut, L.C. L'Olivier en Algérie; Mustapha: Alger, France, 1900.

27. Cipriani, G.; Marrazzo, M.T.; Marconi, R.; Cimato, A.; Testolin, R. Microsatellite markers isolated in olive (Olea europaea L.) are suitable for individual fingerprinting and reveal polymorphism within ancient cultivars. Theor. Appl. Genet. 2002, 104, 223-228. [CrossRef] [PubMed]

28. La Mantia, L.; Lain, T.; Caruso, T.; Testolin, R. SSR-based DNA fingerprints reveal the genetic diversity of Sicilian olive (Olea europaea L.) germplasm. J. Hortic. Sci. Biotechnol. 2005, 80, 628-632. [CrossRef]

29. Muzzalupo, I.; Stefanizzi, F.; Salimonti, A.; Falabella, R.; Perri, E. Microsatellite markers for identification of a group of Italian olive accessions. Sci. Agric. 2009, 66, 685-690. [CrossRef]

30. Dominguez-Garcia, M.; Laib, M.; De la Rosa, R.; Belaj, A. Characterisation and identification of olive cultivars from North-eastern Algeria using molecular markers. J. Hortic. Sci. Biotechnol. 2012, 87, 95-100. [CrossRef]

31. Frend, W.H.C.; Camps-Fabrer, H. L'Olivier et l'Huile dans l'Afrique romaine. Algiers: Gouvernement Général de l'Algérie, 1953. Pp. 95, with 19 plates and 2 maps. c. 16s. 6d. J. Rom. Stud. 1954, 44, 153-154. [CrossRef]

32. Camps-Fabrer, H. L'olivier et son importance économique dans l'Afrique antique. Options Méditerranéennes 1974, $24,21-28$.

33. Hannachi, H.; Breton, C.; Msallem, M.; El Hadj, S.B.; El Gazzah, M.; Bervillé, A. Genetic Relationships between Cultivated and Wild Olive Trees (Olea europaea L. var europaea and var. sylvestris) Based on Nuclear and Chloroplast SSR Markers. Nat. Res. 2010, 1, 95-103. [CrossRef]

34. Belaj, A.; Muñoz-Diez, C.; Baldoni, L.; Satovic, Z.; Barranco, D. Genetic diversity and relationships of wild and cultivated olives at regional level in Spain. Sci. Hortic. 2010, 124, 323-330. [CrossRef]

35. Sefc, K.M.; Lopes, M.S.; Mendonça, D.; Rodrigues Dos Santos, M.; Da Câmara Machado, M.; Da Câmara Machado, A. Identification of microsatellites loci in olive (Olea europaea L.) and their characterisation in Italian and Iberian olive trees. Mol. Ecol. 2000, 9, 1171-1193. [CrossRef] [PubMed]

36. Carriero, F.; Fontanazza, G.; Cellini, F.; Giorio, G. Identification of simple sequence repeats (SSRs) in olive (Olea europaea L.). Theor. Appl. Genet. 2002, 104, 301-307. [CrossRef] [PubMed] 
37. Mariotti, R.; Cultrera, N.G.M.; Mousavi, S.; Baglivo, F.; Rossi, M.; Albertini, E.; Alagna, F.; Carbone, F.; Perrotta, G.; Baldoni, L. Development, evaluation, and validation of new EST-SSR markers in olive (Olea europaea L.). Tree Genet. Genomes 2016, 12, 120. [CrossRef]

38. Trujillo, I.; Ojeda, M.A.; Urdiroz, N.M.; Potter, D.; Barranco, D.; Rallo, L.; Diez, C.M. Identification of the Worldwide Olive Germplasm Bank of Córdoba (Spain) using SSR and morphological markers. Tree Genet. Genomes 2014, 10, 141-155. [CrossRef]

39. Ben Mohamed, M.; Zelasco, S.; Ben Ali, S.; Guasmi, F.; Triki, T.; Conforti, F.L.; Kamoun Naziha, G. Exploring olive trees genetic variability in the South East of Tunisia. Genet. Mol. Res. 2017, 16, 16039850. [CrossRef]

40. Mousavi, S.; Mariotti, R.; Regni, L.; Nasini, L.; Bufacchi, M.; Pandolfi, S.; Baldoni, L.; Proietti, P. The First Molecular Identification of an Olive Collection Applying Standard Simple Sequence Repeats and Novel Expressed Sequence Tag Markers. Front. Plant. Sci. 2017, 8, 1283. [CrossRef] [PubMed]

41. Sneath, P.H.; Sokal, R.R. Numerical Taxonomy the Principles and Practice of Numerical Classification, 1st ed.; W. H. Freeman and Company: San Francisco, CA, USA, 1973; p. 573.

42. Rodrı'guez-Ramillo, S.T.; Wang, J. The effect of close relatives on unsupervised Bayesian clustering algorithms in population genetic structure analysis. Mol. Ecol. Res. 2012, 12, 873-884. [CrossRef]

43. Kalinowski, S.T.; Taper, M.L.; Marshall, T.C. Revising how the computer program CERVUS accommodates genotyping error increases success in paternity assignment. Mol. Ecol. 2007, 16, 1099-1106. [CrossRef] [PubMed]

44. Yeh, F.C.; Yang, R.C.; Boyle, T.B.; Ye, Z.; Mao, J.X. Popgene, the User-Friendly Shareware for Population Genetic Analysis; Molecular Biology and Biotechnology Centre, University of Alberta: Edmonton, AB, Canada, 1997; p. 10.

45. Peakall, R.; Smouse, P.E. GENALEX 6: Genetic analysis in Excel. Population genetic software for teaching and research. Mol. Ecol. Notes 2006, 6, 288-295. [CrossRef]

46. Pritchard, J.K.; Stephens, M.; Donnelly, P.J. Inference of population Structure using multilocus genotype. Genetics 2000, 155, 945-959. [PubMed]

47. Earl, D.A.; Von Holdt, B.M. Structure Harvester, a website and program for visualizing STRUCTURE output and implementing the Evanno method. Cons. Genet. Resour. 2012, 4, 359-361. [CrossRef]

48. Evanno, G.; Regnaut, S.; Goudet, J. Detecting the number of clusters of individuals using the software Structure: A simulation study. Mol. Ecol. 2005, 14, 2611-2620. [CrossRef]

49. Cornuet, J.M.; Pudlo, P.; Veyssier, J.; Dehne-Garcia, A.; Gautier, M.; Leblois, R.; Marin, J.M.; Estoup, A. DIYABC v2.0: A software to make approximate Bayesian computation inferences about population history using single nucleotide polymor-phism, DNA sequence and microsatellite data. Bioinformatics 2014, 30, 1187-1189. [CrossRef] [PubMed] 